\title{
Selection of Optimum Welding Condition using Experimental Design Methods for the Automatic GMA Welding Process
}

\author{
Zong-Liang Liang1, Tae-Jong Yun¹, Won-Bin Oh¹, Bo-Ram Lee1, Byeol Lim¹, Bock-Hee Park², Ill-Soo \\ Kim $^{1}$ \\ ${ }^{1}$ Department of Mechanical Engineering, Mokpo National University \\ 1666 Yeongsan-ro, Cheonggye-myeon, Muan-gun, Jeollanam-do, 58554, South Korea \\ yzl143017@mokpo.ac.kr; tjyun@mokpo.ac.kr; wboh@mokpo.ac.kr; boramess@mokpo.ac.kr; zxzc1020@mokpo.ac.kr \\ ${ }^{2}$ Center for Women In Science, Engineering and Technology, Mokpo National University \\ 1666 Yeongsan-ro, Cheonggye-myeon, Muan-gun, Jeollanam-do, 58554, South Korea \\ bhpark@mokpo.ac.kr; ilsookim@mokpo.ac.kr
}

\begin{abstract}
The welding parameters directly affect the weld forming and the joint performance in GMA (Gas Metal Arc) welding. Because of the many parameters involved in the automatic arc welding process, it is often not realistic to use traditional experimental methods such as full factorial design. Therefore, it is important to find the good experimental design method for determining the welding parameters that obtain an optimal joint quality with a minimal number of experiments.

Therefore, this study is aimed at investigating the effect of DOE (Design of Experiment) methods on bead width of mild steel parts welded by the automatic GAM welding process. Taguchi method was employed to study effect the welding parameters and optimization of bead width, while Box-Behnken method was utilized to develop a mathematical model relating the bead width to welding parameters such as welding voltage, arc current, welding speed and CTWD (Contact Tip to Work Distance). The S/N (signal-to-noise) ratio and the ANOVA (Analysis of Variance) were employed to find the optimal bead width in automatic GAM welding process. Confirmation tests were carried out illustrating the effectiveness of the Taguchi method. The results showed that welding current mainly affected the bead width. The predicted bead width of $3.12 \mathrm{~mm}$ was in agreement with the confirmation tests. With the regression coefficient analysis in the Box-Behnken design, a relationship between bead width and welding parameters was obtained. A second-order empirical model has also been established between the welding parameters and the bead width as welding quality. The developed model is adequate to navigate the design space.
\end{abstract}

Keywords: GMA welding, DOE, Taguchi method, Box-behnken design method, Regression models ANOVA test.

\section{Introduction}

The GMA welding process is the most widely used welding process that yields coalescence of metals by heating with a welding arc between a continuous filler metal (consumable) electrode and the workpiece. The continuous wire electrode which is drawn from a reel by an automatic wire feeder, and then fed through the contact tip inside the welding torch, is melted by the internal resistive power and heat transferred from the welding arc. Technology advancements to set optimal welding parameters automatically based on material thickness and wire diameter, allow focusing on proper technique while achieving smooth, spatter-free starts, a common problem area for occasional welders. However, not all welding machines have this capability. One of the important tasks in the automatic GMA welding process is to understand how welding parameters affect the bead geometry and subsequently develop the suitable models for predicting the desired outputs as welding quality [1]. High quality welds by carefully choosing and closely controlling welding parameters may be made in all circumstances for automatic GMA welding process. Not only the welding parameters determine the shape of GMA welding bead 'keyhole', due to the combination of these parameters control the heat input, but also the welding parameters directly affect the weld forming and the joint performance. Because of the many parameters involved in the automatic arc welding process, it is often not realistic to use traditional experimental methods such as full factorial design. Therefore, it is important to find the good experimental design method for determining the welding parameters that obtain an optimal joint quality with a minimal number of experiments. DOE (Design of Experiment) is widely used to predict the weld geometry and mechanical properties in many welding process [2]. Therefore, in this work DOE is used to develop models to predict the heat input and to describe the bead width for automatic GMA welding of medium carbon steel. The welding parameters 
taken into considerations are welding voltage (I), arc current (V), welding speed (S) and CTWD (C) [3]. In order to get good bead width, it becomes necessary to employ optimisation techniques to find optimal welding parameters and develop a symbolic model between the bead width and the welding parameters applied for the automatic GMA welding process in advance with high rates of reproducibility. Taguchi and response surface methods can conveniently be used for this purpose.

Therefore, the objective of this paper is to propose a good experimental design models for the lab joints in the automatic GMA welding process by DOE method. The settings of the welding parameters were done following the Taguchi and Box-Behnken methods. OA (Orthogonal Arrays), the S/N ratios and the ANOVA were employed to find the optimal level that would lead to optimal bead width and to analysis the effect of the welding parameters on bead width. Confirmation tests with the optimal levels of welding parameters were carried out in order to illustrate the effectiveness of the Taguchi's optimization technique.

\section{Experimental Method}

The chosen welding parameters in this study are as follows: welding current (135-195 A), arc voltage (18-28 V), welding speed $(400-800 \mathrm{~mm} / \mathrm{min})$, CTWD $(12-18 \mathrm{~mm})$ and the responses considered are bead width as welding quality. Table 1 shows the welding parameters and experimental design levels used. There are four welding parameters and each of them has been set at its three levels.

Table 1: Welding parameters and their levels for an automatic GMA welding process.

\begin{tabular}{|l|l|l|l|l|l|}
\hline Welding parameter & Symbol & Unit & Level 1 & Level 2 & Level 3 \\
\hline Welding current & $\mathrm{I}$ & $\mathrm{A}$ & 135 & 165 & 195 \\
\hline Arc voltage & $\mathrm{V}$ & $\mathrm{V}$ & 18 & 23 & 28 \\
\hline Welding speed & $\mathrm{S}$ & $\mathrm{mm} / \mathrm{min}$ & 400 & 600 & 800 \\
\hline CTWD & $\mathrm{C}$ & $\mathrm{mm}$ & 12 & 15 & 18 \\
\hline \multirow{2}{*}{ Fixed parameters } & $\diamond \begin{array}{l}\text { Torch angle to Surface: } 90^{\circ} \\
\end{array}$ & $\checkmark$ Shielding gas flow rate : 18 1/min \\
\hline
\end{tabular}

\subsection{Taguchi Design}

The experiment was designed based on a three level Taguchi design with full replication. Thus, total L9 $\left(3^{4}\right)$ combinations of the welding parameters were to be considered for the Taguchi design [4]. Table 2 show the experimental data collected as per the above DOE employed. Taguchi was employed for analyzing the mean and S/N ratio using conceptual approach that involved graphing the effects. Analysis of the mean S/N ratios was used to identify the most significant parameters and interaction effects. The direction of improvement was determined through analysis and finally the optimal parameters were predicted.

\subsection{Box-Behnken Design}

Experiments were carried out using the Box-Behnken design, which allowed manipulation of the experimental conditions of the integer form in the response surface method. The factors and level employed in the experiments are shown in the Table 1, while, the CTWD was fixed at $18 \mathrm{~mm}$ based the results of Taguchi design. Thus, a total of 15 experiments were conducted according to the experimental design. The tests for significance on individual model coefficients and the lack of fit tests were performed using the same statistical techniques. The test for significance of the regression models and the F-test for testing significance on individual coefficient were carried out using the same statistical methods. By selecting the step-wise regression method, which eliminated the insignificant model terms automatically, the reduced quadratic models would be employed the analysis of variance of each response and showed the significant model terms $[5,6]$. 


\section{Results and Discussion}

\subsection{Results for Taguchi Method}

In Taguchi method, the term 'signal' represents the desirable value while 'noise' denotes 'undesirable' value. The objective of using $\mathrm{S} / \mathrm{N}$ ratio was a measure of performance to develop products and processes insensitive to noise factors. Welding parameter settings with the highest $\mathrm{S} / \mathrm{N}$ ratio always yielded the optimum quality with minimum variance. The $\mathrm{S} / \mathrm{N}$ ratio, the mean of standard deviation, was employed for significant parameters identified and optimal welding parameter for each characteristic was predicted through $\mathrm{S} / \mathrm{N}$ values and the mean response. It was a performance to select the control levels that managed with the noise. In the present work, the smaller is better quality characteristics for minimize the bead width should be taken for obtaining optimal welding performance. The $\mathrm{S} / \mathrm{N}$ ratio for the smaller is better quality characteristic can be expressed as:

$$
S / N=-10 \log \left[\frac{1}{n} \sum_{i=1}^{n} y_{i}^{2}\right]
$$

Where $y_{i}$ is the collected data through experiments and $n$ represents number of experimental runs. Irrespective of the category of the performance characteristics, the greater $\mathrm{S} / \mathrm{N}$ corresponds to the better performance characteristics. Therefore, the optimal level of the welding parameters is the level with the highest $\mathrm{S} / \mathrm{N}$ ratio.

Table 2 indicated the OA, the bead width and their average S/N ratios. Fig. 1 represented the results of S/N ratio analyzed. According to Fig. 1, optimum conditions using SN ratio analysis were selected such as welding current 135A, arc voltage $18 \mathrm{~V}$, welding speed $800 \mathrm{~mm} / \mathrm{min}$, CTWD $18 \mathrm{~mm}$. It might be concluded that the welding parameters influencing the removal of the bead width in the order of their importance are welding current, welding speed, Arc voltage, CTWD orderly.

Table 2: Results of Taguchi method using orthogonal array L9.

\begin{tabular}{|l|l|l|l|l|l|l|}
\hline $\begin{array}{l}\text { Experiment } \\
\text { NO. }\end{array}$ & $\begin{array}{l}\text { Welding current } \\
(\mathrm{A})\end{array}$ & $\begin{array}{l}\text { Arc voltage } \\
(\mathrm{V})\end{array}$ & $\begin{array}{l}\text { Welding speed } \\
(\mathrm{mm} / \mathrm{min})\end{array}$ & $\begin{array}{l}\text { CTWD } \\
(\mathrm{mm})\end{array}$ & $\begin{array}{l}\text { Bead width } \\
(\mathrm{mm})\end{array}$ & S/N Ratio \\
\hline 1 & 135 & 18 & 400 & 12 & 7.86 & -17.9085 \\
\hline 2 & 135 & 23 & 600 & 15 & 5.41 & -14.6639 \\
\hline 3 & 135 & 28 & 800 & 18 & 5.41 & -14.6639 \\
\hline 4 & 165 & 18 & 600 & 18 & 5.3 & -14.4855 \\
\hline 5 & 165 & 23 & 800 & 12 & 5.51 & -14.8230 \\
\hline 6 & 165 & 28 & 400 & 15 & 11.51 & -21.2215 \\
\hline 7 & 195 & 18 & 800 & 15 & 8.94 & -19.0268 \\
\hline 8 & 195 & 23 & 400 & 18 & 17.98 & -25.0958 \\
\hline 9 & 195 & 28 & 600 & 12 & 14.53 & -23.2453 \\
\hline
\end{tabular}

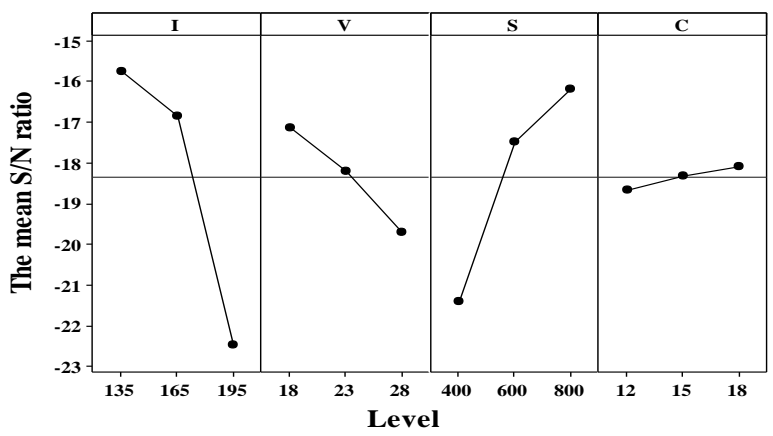

Fig. 1: The analysed results of $\mathrm{S} / \mathrm{N}$ ratio. 


\subsection{Results for Box-Behnken Design}

Box-Behnken design was applied to the experimental data using statistical software, Minitab [7]. Linear and secondorder polynomials were fitted to the experimental data to obtain the regression equations. The sequential F-test and lackof-fit test were used in selecting the best models. A step-wise regression method was employed to fit the second-order polynomial equation to the experimental data and to identify the relevant model terms. Table 3 is represented variance (ANOVA) results for bead width for Box-Behnken. Based on the ANOVA analysis, it might be known that the significance of the regression model was less than 0.001, which means that the regression equation should be extremely significant, but the lack of fit was indicated that the experimental points can't all be described by the model, was less than 0.05. In order to solve the problem of lack of fit of the developed model, increasing the order of the regression model would be required. Therefore, third-order regression model [8] was chose. The adequate precision values for the fitted value which related to the suitability of models were significantly higher than 4. And based on the ANOVA analysis, the results which studied prediction for mean bead width was shown in the Fig. 2, and the optimal wielding parameters for a given bead welding were selected welding current $145 \mathrm{~A}$, arc voltage $18 \mathrm{~V}$, welding speed $800 \mathrm{~mm} / \mathrm{min}$.

Table 3: Variance (ANOVA) results for bead width for Box-Behnken.

\begin{tabular}{|l|l|l|l|l|l|l|l|l|}
\hline Source & df & Seq SS & $\begin{array}{l}\text { Percentage } \\
\text { contribution }\end{array}$ & Adj SS & Adj MS & F Value & P-value & \\
\hline Model & 10 & 207.437 & $99.99 \%$ & 207.437 & 20.7437 & 2701.66 & $<0.0001$ & Significant \\
\hline Welding current(I) & 1 & 102.46 & $49.39 \%$ & 16.386 & 16.3857 & 2134.08 & $<0.0001$ & Significant \\
\hline Arc voltage(V) & 1 & 21.912 & $10.56 \%$ & 5.608 & 5.6083 & 730.43 & $<0.0001$ & Significant \\
\hline Welding speed(S) & 1 & 41.542 & $20.02 \%$ & 0.138 & 0.1385 & 18.03 & 0.0130 & Significant \\
\hline I $\times$ I & 1 & 29.768 & $14.35 \%$ & 29.754 & 29.7545 & 3875.23 & $<0.0001$ & Significant \\
\hline $\mathrm{V} \times \mathrm{V}$ & 1 & 1.204 & $0.58 \%$ & 5.977 & 5.9767 & 778.40 & $<0.0001$ & Significant \\
\hline $\mathrm{S} \times \mathrm{S}$ & 1 & 1.934 & $0.93 \%$ & 1.934 & 1.9341 & 251.90 & $<0.0001$ & Significant \\
\hline $\mathrm{I} \times \mathrm{V}$ & 1 & 0.036 & $0.02 \%$ & 6.789 & 6.7888 & 884.18 & $<0.0001$ & Significant \\
\hline $\mathrm{I} \times \mathrm{S}$ & 1 & 1.071 & $0.52 \%$ & 1.071 & 1.0712 & 139.52 & $<0.0001$ & Significant \\
\hline $\mathrm{V} \times \mathrm{S}$ & 1 & 0.757 & $0.36 \%$ & 0.757 & 0.7569 & 98.58 & 0.0010 & Significant \\
\hline $\mathrm{I} \times \mathrm{I} \times \mathrm{V}$ & 1 & 6.753 & $3.25 \%$ & 6.753 & 6.7528 & 879.49 & $<0.0001$ & Significant \\
\hline Error & 4 & 0.031 & $0.01 \%$ & 0.031 & 0.0077 & - & - & - \\
\hline Lack-of Fit & 2 & 0.02 & $0.01 \%$ & 0.02 & 0.0102 & 1.95 & 0.339 & $\begin{array}{l}\text { Not } \\
\text { significant }\end{array}$ \\
\hline Pure error & 2 & 0.01 & $0.01 \%$ & 0.01 & 0.0052 & - & - & - \\
\hline & & & & & & & & \\
\hline Total & 14 & 207.468 & $100.00 \%$ & - & - & - & - & - \\
\hline
\end{tabular}

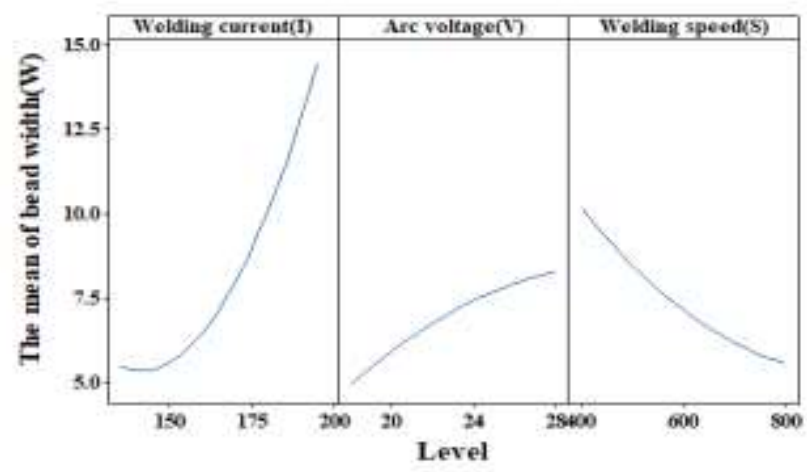

Fig. 2: The analyzed results of mean bead width. 


\section{Conclusion}

In present work, optimization of bead width has been carried out using DOE in the Automatic GMA welding process. A series of experiments has been conducted for generation of dataset. Taguchi method uses a standard orthogonal matrix for robust three-time design. The $\mathrm{S} / \mathrm{N}$ ratio was the main experimental robustness evaluation index, ensuring that all experimental factor information and test factors affecting the experimental objectives are determined on the impact on the experimental objectives by a small number of experiments. Optimal parametric welding condition was (i.e. welding current 135A, arc voltage $18 \mathrm{~V}$, welding speed $800 \mathrm{~mm} / \mathrm{min}$, CTWD $18 \mathrm{~mm}$ ) obtained by analysis results of S/N ratio for minimizing the response as bead width, and confirmatory experiment results confirmed the validity of the optimal results obtained. The BoxBehnken response surface method was based on the rigorous mathematical theory, and mainly applied to the nonlinear regression fitting in the scope of the normative experiment, and the range of values for each factor should be small, it is possible to avoid ignoring significant changes between levels. In addition, the developed model can effectively be recognized the insignificant main effect, interaction effect and quadratic effect, thus greatly reducing the complexity of the problem and improving the experimental efficiency. Based on the ANOVA analysis, the coefficient of correlation $\left(\mathrm{R}^{2}\right)$ for the developed model is observed in excess of 0.99 which inspire confidence in the developed model. The predicted and adjusted $\mathrm{R}^{2}$ values for the response model were in reasonable agreement which again validates the fitness of developed models. The low value of C.V. obtained for all the models indicated the improved precision and reliability of the experiments performed. The adequate precision values for the fitted value, are significantly less than 0.05 indicating the suitability of models for future prediction. More studies may be needed to obtain closer matching in the future. Hence, it was concluded that the developed symbolic model was fairly successful and virtue for specifying the bead width under different welding parameters as welding quality.

\section{Acknowledgements}

This work was supported by the Project of Technology Development for Industry Core (No.20004100, Package Concept of Pipe Spools, Platform as a Service, Digital Twin, Big Data) funded By the Ministry of Trade, Industry \& Energy (MOTIE, Korea)

\section{References}

[1] X. M. Zeng, J. Lucas and M.T.C. Fang, "Use of neural networks for parameter prediction and quality inspection in tungsten inert gas welding," Transactions of the Institute of Measurement and Control, vol. 15, no. 2, pp. 87-95, 1993.

[2] H. Rowlands and F. Antony, Application of design of experiments to a spot-welding process. Newport, Wales College Univ., UK, pp. 273-279, 2003.

[3] V. Gunaraj and N. Murugan, "Prediction and optimization of weld bead volume for the submerged arc process - Part 1," Welding Journal, vol. 79, no. 10, pp. 287-294, 2000.

[4] G.S. Peace, Taguchi methods: A hands-on approach to quality engineering. 3rd edition. Addison-Wesley, Inc., New York, 1993

[5] D.C. Montgomery, Design and analysis of experiments. 2nd edition, John Wiley \& Sons, New York, 1984.

[6] A. I. Khuri and J. A. Cornell, Response surfaces design and analysis. 2nd edition, Marcel Dekker, New York, 1996.

[7] Minitab Inc., "User manual of MINITAB statistical software," Release 13.31, State College, PA 16801 USA, 2000.

[8] T. P. Davis and N.R. Draper, "Fitting 3rd order terms to Box-Behnken experiments," Dept. Statistics., Wisconsin University, no. 990, March, 1998. 